a single dose of $300 \mathrm{MBq}{ }^{99} \mathrm{Tc}$-labelled anti-TNF $\alpha \mathrm{MAb}$ and whole body images and spot views were obtained with a doubleheaded gamma camera.

Results Prominent uptake of the radiolabeled anti-TNF $\alpha$ MAb was clearly visible in inflamed joints of all patients examined. The distribution of the label was compatible with binding to both soluble and membrane-bound TNF $\alpha$. To elucidate the latter, displacement studies are now in process.

Conclusion Our results show that scintigraphic detection of inflammation with anti-TNF $\alpha$ MAb is feasible. The potential use of this technique to monitor disease activity and response to therapy deserves further investigation.

\section{AB0200 DO ULTRASOUND-GUIDED CORTICOSTEROID INJECTIONS PROVIDE SHORT-TERM RELIEF OF SYMPTOMS IN PATIENTS WAITING TOTAL HIP REPLACEMENT?}

Z Karim, AK Brown, PJO Connor, M Quinn, G Jackson, RJ Wakefield, PG Conaghan, P Emery. Rheumatology and Rehabilitation Research Unit, University of Leeds, Leeds, UK

\subsection{6/annrheumdis-2001.678}

Background Osteoarthritis is the commonest cause of total hip joint replacement. The indication for this procedure is pain and loss of function that has not responded adequately to conservative therapy. Maintaining good muscle strength and optimising weight are important to good outcome post-surgery. This is difficult when symptoms reduce patients? mobility. Corticosteroid injections are commonly used for short-term relief of joint symptoms.

Objectives The primary aim of this pilot study is to determine whether corticosteroid injections improve pain and function in this group, and to identify any baseline features that predict response.

Methods Patients with osteoarthritis or stable rheumatoid arthritis awaiting total hip replacement are invited to take part. Patients with a contraindication to intraarticular corticosteroid or impending replacement (within 3 months) are excluded. Baseline data collected includes the WOMAC index, VAS for pain and stiffness during rest and walking, and SF-36. These outcome measures are repeated at 2, 6 and 12 weeks. Patients have 40 $\mathrm{mg}$ triamcinolone with $2 \mathrm{mls}$ of $1 \%$ lignocaine via ultrasoundguided injection into the hip. Degree of capsular distension, a possible marker of synovitis, is documented by US. Conventional radiographs of the affected hip are also obtained to assess degree of damage.

Results 6 patients have been recruited to date in this ongoing study. Pain scores and functional changes have improved. Our experience suggests those with capsular distension are more likely to respond.

Conclusion Any reduction in patient symptoms that improves pre-operative pain and mobility should improve patient wellbeing and could also improve outcome post-surgery. Any predictor of response would allow the application of more accurate risk-benefit assessment for this procedure.

\section{AB0201 CAPILLAROSCOPIC EXAMINATION IN ARTHRITIS PSORIATICA}

Z Tarján, É Koó, I Ujfalussy. II. Rheumatology, Polyclinic of the Hospitaller Brothers of St. John of God in Budapest, Hungary, Budapest, Hungary

\subsection{6/annrheumdis-2001.679}

Background The capillaroscopic examination gives a possibility to find a correlation between the groups of ilnesses and the change of microcirculation based on a non-invasive method. In the publications are mentioned very seldom that decrease of the capillary loops' length and diameter, the twisting of venous side and the decrease of capillaries' density are the fundamental variables in the case of capillaroscopic examination of Arthritis Psoriatica's (AP) patients.

Objectives The study was made on 34 verified AP's patients (20 male, 14 female) selected by the basis of the ARA's criterias in the authors Department of AP Outpatient. Dysqualifying criteria were the metabolic diseases, the cardiovascular diseases and smoking.

Methods The period of psoriasis and arthritis was studied, and the capillary was classified on the basis of morphological criterias (hairpin-shaped, spiral, and bushy appearance) their lengthened and extended forms (arterial and venous side, the length of apical region), the density of capillaries, tearness and continousness of flow. Leitz's microscope was used for examination (35x magnification, max. 100x). The nailfold was lightened with cold light, further the paraffin oil was used to the surface.

Results It was found that the period of dermatological symptoms are proportional to the number of spiral form of capillaries $(r=$ $0.371, \mathrm{p}<0.05)$. The length and width of capillaries were independent from the dermatological and arthritic symptoms (NS = $\mathrm{p}$ 0.05). In the case of lengthened frame, the number of bushy forms were less than the others. Then the number of the capillaries loops were decreased ( $\mathrm{p}<0.05$ ).

Conclusion It is accepted in general, that the decrease of the capillaries's numbers as well as the morphological changes -as a typical form of the AP's patients -are in correlation significantly with the period of psoriasis. Disagrees with others previous publications, the authors did not find significant difference in the size of capillary loops comparing to the normal control.

\section{AB0202 THE INCREASING USE OF ULTRASONOGRAPHY TO GUIDE CORTICOSTEROID INJECTIONS}

AK Brown, Z Karim, MA Quinn, RW Wakefield, PG Conaghan, P O'Connor, P Emery. Rheumatology and Rehabilitation Research Unit, University of Leeds, Leeds, UK

\subsection{6/annrheumdis-2001.680}

Background Local corticosteroid injection is a standard treatment for joint and soft tissue inflammation. However, these injections are often inaccurately placed and this can affect clinical outcome. Ultrasonography (US) has the ability to precisely identify local pathology, thereby improving diagnosis and is also able to accurately guide placement of corticosteroid injections. In our unit, a dedicated rheumatology US machine is available in the out-patient department operated by experienced rheumatology research fellows trained in musculoskeletal US.

Objectives To evaluate the number, site and indication for USguided soft tissue and intra-articular corticosteroid injection compared with the standard 'blind' clinical approach.

Methods Consecutive patients receiving soft tissue and intraarticular corticosteroid injection in the rheumatology out-patient 